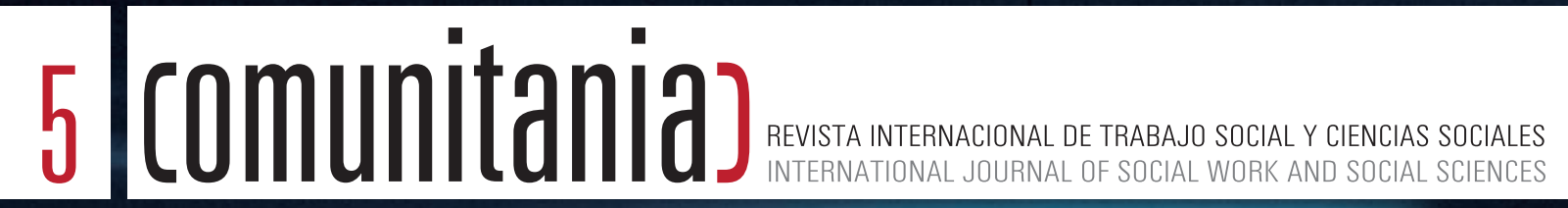

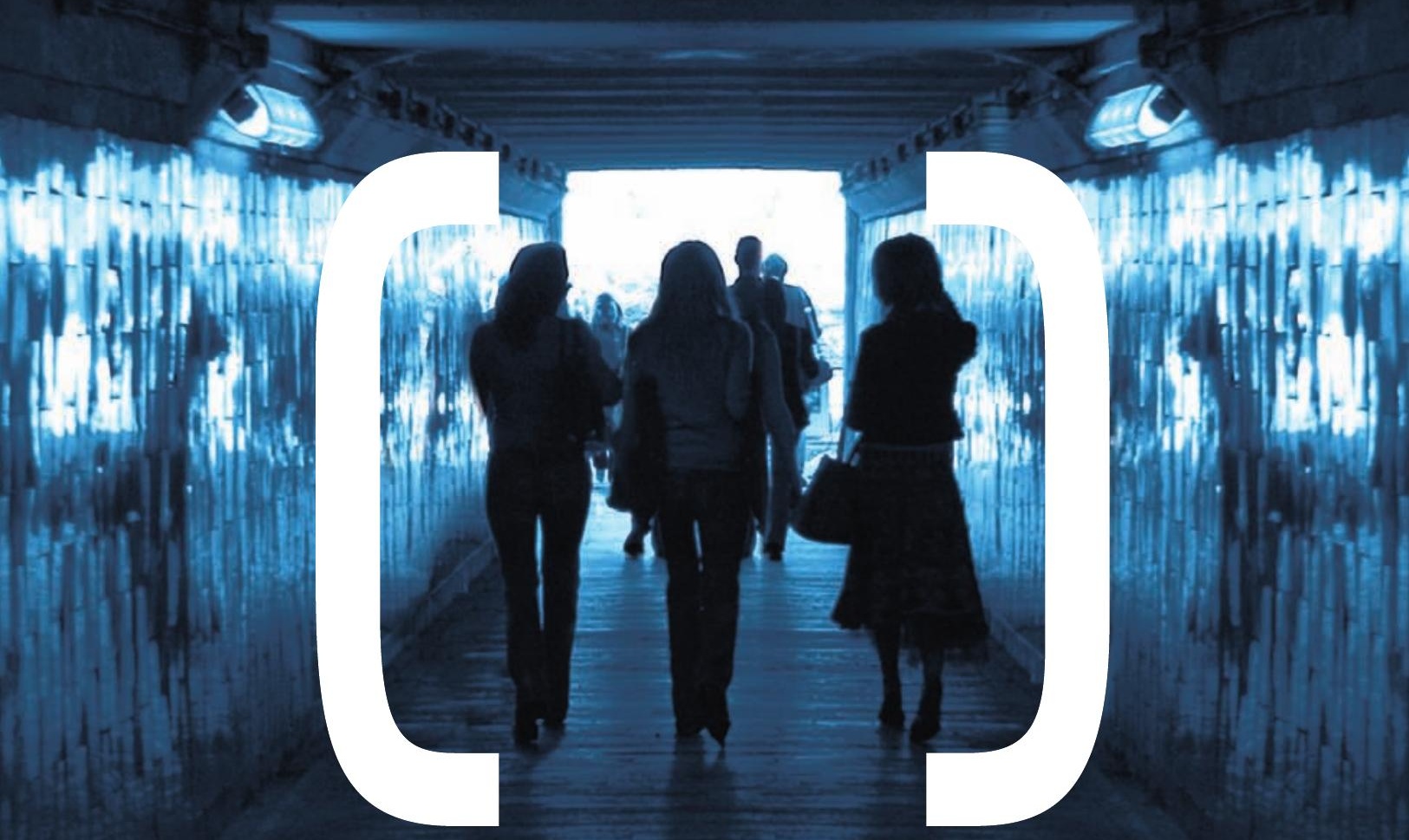

EGUZKI URTEAGA | RODRIGO ANDRÉS | ÁNGELES MARTíNEZ | Ma INMACULADA LÓPEZ | ALEJANDRO CABELLO MARÍA PAZ GARCÍA-LONGORIA | REYNA LIZETH VÁZZUEZ | ARNULFO SÁNCHEZ | EVA SOTOMAYOR | YOLANDA DE LA FUENTE MARTA GARCÍA | Ma LUISA GRANDE | TOMÁS ALBERICH | KARLA SÁENZ | DELIA TÉLLEZ | ANTONIO GUTIÉRREZZ 


\title{
Elementos del proceso de mediación que favorecen a su implementación como política social Elements of the mediation process that benefits implementation as social policy
}

Paris Alejandro Cabello Tijerina*

* Universidad Autónoma de Nuevo León (México). paris_cabello@hotmail.com

\begin{abstract}
Abstrac:
With the implementation of mediation as social policy as a method for resolving conflicts that arise in the bosom of the societies, reinforces the social fabric avoiding the emergence of new conflicts, moreover, persons participating in the mediation procedure acquire tools that enhance dialogue, solidarity and cooperation that would benefit the appearance of relations peacefulto strengthen the structures for the establishment of a culture of peace.

The elements are equity, impartiality, accessibility of Justice, dialogue, peace and active role in the construction of conventions, from our perspective, some of the elements of the mediation process that most favor government implementation as public social policy. This research aims to show which of the elements comprising our hypothesis are the most prominent, to achieve our objective, we used the so-called qualitative research interview with depth instrument throwing that equity, dialogue, access to justice and peace, are the most important elements to consider mediation as social policy.
\end{abstract}

Keywords: Mediation, social policy, justice, peace, ADR.

\section{Resumen:}

Con la implementación de la mediación como política social como método para resolver los conflictos que surjan en el seno de las sociedades, se refuerza el tejido social evitando la aparición de nuevos conflictos, además, las personas que participan en el procedimiento de mediación adquieren herramientas que potencian el diálogo, la solidaridad y la cooperación que beneficiarían a la aparición de relaciones pacificas, fortaleciendo las estructuras para el establecimiento de una cultura de paz.

Los elementos equidad, imparcialidad, accesibilidad de la justicia, el diálogo, la pacificación y el rol activo en la construcción de los convenios, son desde nuestra perspectiva, algunos de los elementos del proceso de mediación que más favorecen a su implementación gubernamental como política pública social. Esta investigación pretende mostrar cuales de 
los elementos que integran nuestra hipótesis son los más destacados; para lograr nuestro objetivo, se utilizó el instrumento de investigación cualitativa denominado entrevista a profundidad arrojando que la equidad, el diálogo, el acceso a la justicia y la pacificación, son los elementos más importantes para considerar la mediación como política social.

Palabras clave: Mediación, política social, justicia, paz, MASC.

\section{Article info:}

Received: 16/10/2012 / Received in revised form: 29/11/2012

Aceppted: 10/12/2012 / Published online: 20/02/2013

DOI: http://dx.doi.org/10.5944/comunitania.5.5

\section{INTRODUCCIÓN}

La presente investigación pretende contribuir al fortalecimiento de una cultura de paz, proponiendo implementar estrategias de resolución pacífica de conflictos como la mediación, considerándola como política social que incida en la transformación positiva de los conflictos. La herramienta idónea, el diálogo y los valores: tolerancia, cooperación, participación activa de la sociedad, solidaridad y el acercamiento de la justicia a la ciudadanía, serán los elementos indispensables para solucionar de manera efectiva, pronta, económica y equitativa los conflictos de la sociedad del siglo XXI.

La mediación comunitaria debiera ser considerada una política social que fortalezca la construcción de la cultura de paz, por tanto, se considera que la equidad, la imparcialidad, la accesibilidad a la justicia, el diálogo, la pacificación y la participación activa de los involucrados en la mediación, son los elementos del proceso de mediación que más favorecen a su implementación como política social.

Para la comprobación de nuestra hipótesis, se aplicarán una serie de entrevistas a profundidad, que evidencien cuales de éstos elementos del proceso de mediación son los que más se destacan, para que los encargados en la creación de las políticas públicas sociales los tomen en cuenta a la hora de los debates previos a su elaboración.

Al considerar la mediación comunitaria como una política social y que la misma sea implementada como tal, se estaría beneficiando a una gran parte de las sociedades modernas, que demandan procedimientos eficaces que gestionen los conflictos de manera positiva, para devolver el rol activo a las partes en conflicto, y así cumplir con el paradigma jurídico del siglo XXI que busca que sean las propias personas las que puedan resolver sus conflictos. 


\section{LA MEDIACIÓN COMO POLÍTICA SOCIAL}

La implementación de la mediación como política pública social, potencia la participación ciudadana en la prevención y gestión de los conflictos que surgen en el seno de las sociedades, convirtiéndose en un medio eficaz para abordar la situación de crisis de la impartición de justicia y fortaleciendo la construcción de una cultura de paz.

En el presente epígrafe, se expondrá la peculiaridad de la mediación comunitaria que pudiera permitirnos considerarla una política social, que con su implementación auxiliaría en la consecución de la cultura de paz, al impactar en los diversos métodos alternativos priorizando su utilización como opciones para solucionar sus conflictos.

La mediación puede ser definida como un método alternativo para la transformación pacífica de los conflictos fundamentada en un proceso comunicacional en el que interviene una tercera persona denominada mediador que guía, orienta y ayuda a las partes inmersas en el conflicto, a que colaboren entre sí, a través de técnicas que potencian la participación y el empoderamiento de las mismas, logrando que sean ellas las que elaboren una solución positiva que ponga fin a su conflicto, fortaleciendo el tejido y la cohesión social, y a la instauración de una cultura de paz.

Así mismo, Teresa Montagut (Política Social. Una introducción. 2008) define la política social como aquella política relativa a la administración pública de la asistencia, es decir, al desarrollo de servicios y prestaciones que intentan paliar determinados problemas sociales 0 , de una forma más modesta, perseguir objetivos que generalmente son percibidos como respuesta a tales problemas.

Como podemos observar en ambas definiciones, uno de los objetivos es solucionar positivamente los conflictos paliando las carencias que manifiestan las sociedades, logrando con ello, fortalecer su tejido social y cohesionarlos.

\section{ANTECEDENTES DE LA MEDIACIÓN}

La mediación o una institución muy similar a la misma, ha sido utilizada aunque en una forma muy rudimentaria desde tiempos muy remotos, en relación a esto, Six (Le temps des médiateurs 2003) menciona que la mediación ha existido siempre. Siempre ha habido, en las tribus o poblados, sabios a quienes se recurría con toda naturalidad, quienes aportaban sosiego a los miembros de su comunidad, personajes que con su actuar, gestionaban los conflictos que se suscitaban en sus comunidades, facilitando la interacción positiva entre sus miembros impulsando cimientos de fraternidad. De hecho Deborah Kolb titula el capítulo inicial de su libro dedicado a los mediadores "la segunda profesión más vieja del mundo" y señala que, desde el primer instante en que alguien mantuvo una disputa con su semejante, surgieron los mediadores para aconsejar el uso de la razón por encima de las armas (Boque Torremorell 2003). 
A través de la historia, grandes civilizaciones han procurado que los principios de justicia y equidad constituyan los cimientos y pilares de las sociedades, es dentro de este marco donde encontramos los métodos alternos para las solución de conflictos.

Sin duda, las filosofías religiosas desempeñaron un papel muy importante para la conservación de esos sistemas informales que se habían estado perdiendo dando paso al monopolio de la justicia por parte del Estado. Diversos grupos religiosos han establecido históricamente sus propios sistemas alternativos para resolución de desavenencias (Folberg y Taylor 1996).

El hombre al ser un sujeto social es cambiante, el simple transcurso del tiempo va modificando las necesidades, conductas, costumbres, características de las sociedades, es por eso que la mediación ha tenido diversos cambios, pero la esencia sigue siendo la misma, resolver conflictos por medio del diálogo.

No es hasta finales del siglo XIX y principios del siglo $X X$, que la práctica de esas formas resolutorias permitiera la formalización de la mediación como método para solucionar conflictos.

\section{ANTECEDENTES DE LAS POLÍTICAS SOCIALES}

El sociólogo Danés Gøsta Esping-Andersen (Prólogo 2008), menciona que desde la antigüedad hanexistido las políticas sociales, sin embargo, no es sino hasta el siglo XIX donde se comienzan a configurar las políticas sociales tal como las conocemos hoy en día.

Se podría considerar al ginebrino Sismonde de Sismondi, como el primer teórico de la política social moderna,al manifestar su convicción de que la economía política debiera estar acorde con la ética, aludiendo que era deber del gobierno crear los medios por los cuales se beneficiara al mayor número posible de individuospara que pudieran alcanzar el grado máximo de felicidad y que éste grado se difundiera entre todas las clases sociales (Molina Cano 2007).

Las revueltas sociales, los sistemas económicos, procesos de industrialización, entre otros factores, influyeron en la configuración de las políticas sociales actuales.

\section{LA MEDIACIÓN ¿PUEDE SER UNA POLÍTICA SOCIAL?}

Si partimos de la idea, de que si los conflictos no son afrontados positivamente y que éstos pueden convertirse en obstáculos para el crecimiento y desarrollo de las sociedades, incluso derivar en actos violentos que pongan en peligro la estabilidad política y la cohesión social; la necesidad de que los gobiernos implementen estrategias o programas que gestionen positivamente esos conflictos, además que incul- 
quen valores como el respeto, solidaridad, igualdad, tolerancia, diálogo, entre otros, que fomenten la participación ciudadana y fortalezcan el tejido social, son actividades apremiantes. Por tanto, es indispensable el surgimiento de políticas que solucionen positiva y eficazmente esos conflictos, políticas sociales como el establecimiento de la mediación comunitaria.

La implementación de la mediación comunitaria como una política social, viene a convertirse en uno de los medios más eficaces para la implantación de una cultura de paz en México y España, porque ayuda a combatir entre otras cosas, el rezago en la impartición de justicia al coadyuvar esfuerzos con otros métodos alternativos de solución de conflictos - conciliación, arbitraje, negociación, etc.-, además de fundar un entorno pacífico, transformando los conflictos en ideas, fomentando el diálogo, la empatía, la solidaridad, la noviolencia, la comprensión, la integración, la creatividad, la participación y el consenso, elementos todos de carácter sine qua non de la Paz.

Así mismo, la mediación, al potenciar la participación ciudadana en la búsqueda de opciones que solucionen sus conflictos, fomenta valores como la justicia, solidaridad, igualdad, cooperación, paz, colaboración, empatía y diálogo, que tienen como finalidad lograr del bienestar y cohesión de la ciudadanía, cuidando la existencia y unidad social, a través de un complejo de instituciones o normas mediante las cuales el Estado y los otros órganos públicos tratan de asegurar la paz social, cumple con los requerimientos profesados por Francisco Vito, Otto von Zwiedineck, Alfred Amonn y Weddigen, que deben tener las políticas sociales como finalidad.

La mediación ofrece un modo eficaz de organizar a los individuos alrededor de intereses comunes, y de ese modo crear vínculos y estructuras comunitarias más sólidas (Baruch Bush y Folger 1996) priorizando el diálogo en la resolución de conflictos buscando el establecimiento de la paz social, así mismo, se cumple con la finalidad de la Política del bien común, o como lo apuntaba Zwiedineck, el mantenimiento sano y vigoroso de la sociedad en su unidad como un todo contra el peligro que para ella puede significar la oposición entre sus partes (Rodríguez 1979).

Por tal motivo, se considera que la mediación puede ser considerada una política social que contribuya a la formación de una cultura cívica con actitudes basadas en la participación, la solidaridad y el respeto mutuo. Promoviendo la convicción de que las personas puedan ser actores en la resolución de sus conflictos, vinculando la participación con la aceptación de puntos de vista ajenos y diferentes, creando canales de diálogo que generen una red de integración social y ayuden a detectar de forma temprana los conflictos sociales. ${ }^{1}$

1 Proyecto de Mediación Comunitaria como Política Pública para la Participación Ciudadana, presentado por la Asociación Respuesta para la Paz, en el Concurso de Buenas Prácticas en Dubai 2006. Disponible en: http://habitat.aq.upm.es/bpal/onu06/bp0832.html (visitado el 26/06/2011). 


\section{ELEMENTOS DEL PROCESO DE MEDIACIÓN QUE FAVORECEN A SU IMPLEMENTACIÓN COMO POLÍTICA SOCIAL}

Con la implementación de la mediación comunitaria como política social, se reforzaría el tejido social evitando la aparición de nuevos conflictos, además, las personas que participen en el procedimiento de mediación adquirirán herramientas que potencian el diálogo, la solidaridad y la cooperación que beneficiarían a la aparición de relaciones pacificas, fortaleciendo las estructuras para el establecimiento de una cultura de paz.

Los elementos de la mediación que consideramos más evidentes para su implementación como política pública social son: la equidad, la imparcialidad, accesibilidad a la justicia, el diálogo, la pacificación y el rol activo en la construcción de los convenios.

Para comprobar la aseveración anterior, es ineludible describir primeramente cada uno de esos elementos y aplicar algún instrumento cualitativo; para esta investigación, se utilizará la entrevista a profundidad, método cualitativo de gran uso en las investigaciones sociales, que pretenden explorar en las vivencias, experiencias o conocimientos de personas, para adquirir conocimientos sobre la vida social (J. y Bogdan 1984).

La aplicación del instrumento se llevo a cabo por medio de un muestreo no probabilístico dirigido a un total de 12 sujetos elegidos de acuerdo a su conocimiento en la materia, entre las que encontramos a profesionistas, teóricos, académicos, expertos de la mediación y participantes en la misma, con el objetivo de descubrir cuáles son los elementos de la mediación que más favorecen a su aplicación gubernamental como política pública social.

\section{Equidad}

La equidad en la mediación es un elemento que debiera ser considerado por los agentes encargados en la creación de políticas sociales, porque pretende que tanto el proceso como las resoluciones emanadas del mismo, sean lo más justas e igualitarias posibles, priorizando el diálogo y la participación activa de la sociedad. Carlos Ruiz Sánchez (Manual para la elaboración de políticas públicas 2002) considera esto último como muy importante para asegurar el éxito en la implementación de las políticas públicas, al mencionar que: las acciones de la política pública se deben contemplar con la participación ciudadana, lo que asegura en buena medida el éxito de las políticas, puesto que quienes conocen mejor sus problemas y las formas o maneras de solucionarlos son los individuos o las comunidades; en una palabra, los afectados directamente.

El concepto de equidad es muy amplio y diferente en cada persona, es decir, que lo que es equitativo para algunos puede ser inequitativo para otros. La mediación permite que las partes enfrentadas realicen negociaciones con la intención de solucionar por ellas mismas sus conflictos, buscando desde su perspectiva la solución 
más justa y equitativa. Esto hace pensar que la justicia es más equitativa cuando las partes resuelven con base en un procedimiento no adversarial que cuando se someten a un proceso judicial que aplica estrictamente el derecho (Gorjón Gómez y Sáenz López 2009).

La equidad es un elemento primordial y casi imprescindible para lograr la pacificación (Martín 2011) permitiendo a las partes expresarse con objetividad en un espacio de respeto e igualdad, facilitándoles la creación de opciones que pongan fin a su controversia.

Las características de la mediación permiten acercarse a los ideales de equidad y prontitud -principios básicos de la justicia-, por tanto, es necesario crear una cultura para su aplicación, rompiendo con el modelo rígido adversarial del sistema judicial.

Reconociendo que su aplicación nos acerca más a la justicia, con base en razonamientos de las partes que establecen criterios más equitativos para la resolución del conflicto; razonamientos y sentimientos, así como el equilibrio de intereses y la armonía que se puede lograr en cualquier tipo de relación jurídica nos acercan a la equidad y, por ende, a la justicia (Gorjón Gómez y Sáenz López 2009).

\section{Imparcialidad}

La imparcialidad viene de la palabra imparcial, locución latina compuesta por el prefijo in y la terminación partial, es decir, imparcialidad se refiere a la falta de designio anticipado o de prevención en favor o en contra de alguien o algo, que permite juzgar o proceder con rectitud (Real Academia Española s.f.).

La imparcialidad es una característica fundamental en todo procedimiento de mediación, que recaerá sobre la figura del mediador al convertirse en el tercero ajeno al conflicto que auxiliará a las partes a encontrar la mejor solución a su problemática.

El mediador estará obligado a actuar de manera imparcial ${ }^{2}$, propiciando la igualdad de oportunidades y la comunicación empática y efectiva entre los participantes. ${ }^{3}$

2 Como lo señala el artículo 7 de la Ley Federal de Responsabilidades Administrativas de los Servidores Públicos de los Estados Unidos Mexicanos, que a la letra dice: será responsabilidad de los sujetos de la ley ajustarse, en el desempeño de sus empleos, cargos o comisiones, a las obligaciones previstas en ésta, a fin de salvaguardar los principios de legalidad, honradez, lealtad, imparcialidad y eficiencia que rigen en el servicio público.

3 Artículo 11 fracción VII de la Ley de Métodos Alternos para la Solución de Conflictos del Estado de Nuevo León, México. 
La característica de la imparcialidad en la mediación para solucionar conflictos sociales, debiera ser tomada en cuenta por los encargados de la creación de políticas públicas, cuando pretenden elaborar un programa que busque solucionar de manera eficaz y eficiente la conflictividad social, misma que si no se aborda adecuadamente, pone en peligro la estabilidad política y por ende la disolución de la sociedad.

Si se diseña adecuadamente una política social que instituya las estructuras adecuadas para la solución de los conflictos, y además cuente con una financiación suficiente para el logro de tan loable objetivo, pudiera convertirse en un instrumento para la promoción de la equidad (Ortiz 2007, 1-75) en las sociedades.

Además, las políticas públicas sociales necesitarán invariablemente estar construidas en base a los principios de imparcialidad, equidad, neutralidad y justicia, para poder alcanzar sus resultados deseados, características que cumple la mediación para ser considerada una política pública social.

\section{Accesibilidad a la justicia}

Una de las características de la mediación es su facilidad y flexibilidad como método alternativo para la solución de conflictos y es debido a estas características que podemos afirmar que la mediación facilita el acceso real a la justicia. Esto conlleva a pensar que la justicia es más equitativa cuando las partes resuelven sus diferencias con base a un procedimiento no adversarial, y no cuando se someten a un proceso judicial que aplica estrictamente el derecho, (Gorjón Gómez y Steele Garza, Métodos Alternativos de Solución de Conflictos 2008) es decir, en ocasiones las resoluciones judiciales son contempladas como injustas por las partes, debido a que éstas se basan en criterios generales para casos particulares, lo que en ocasiones produce omisiones para algunos casos concretos. En cambio la mediación se adecua a cada caso particular y son las partes y no un tercero, las que otorgan la solución a los conflictos.

Los investigadores Gorjón y Steele (Métodos Alternativos de Solución de Conflictos 2008) mencionan que cuando las partes conforme a su propia naturaleza y conveniencia y para establecer un acuerdo determinan sus obligaciones y derechos ante la existencia de un conflicto, estaríamos en presencia de una opción real para alcanzar la justicia.

En la actualidad, todavía nos encontramos inmersos en una cultura del litigio que ante la presencia de un conflicto, los involucrados, buscan ganar a toda costa y conciben como imposible una solución en la que ambas partes puedan ganar. La necesidad de ganar, derrotar, salir con el beneficio de la victoria, reconocer que se encuentran en posición de la verdad, se convierte en un fin en sí mismo dificultan- 
do la visualización de otras soluciones (Ríos Martín, Pascual Rodríguez y Bibiano Guillén 2008).

La impartición de justicia ha sido monopolizada por parte del Estado, rezagando los procedimientos aceptados socialmente en la antigüedad, que fungían como mecanismos de regulación o solución de las diferencias nacidas en el seno de las sociedades (Gordillo Santana 2007) entre ellos la mediación, trajo como consecuencia el colapso de los órganos judiciales debido al altísimo índice de conflictos que se tratan judicialmente, impidiendo la satisfacción de la demanda de justicia de la sociedad -problema de la impetración de la justicia-.

Esta crisis de la impartición de la justicia es producida entre otras cosas por su difícil acceso. En toda sociedad y en todo sistema jurídico se debería proveer a la población de modos para solucionar sus conflictos -judiciales o alternativos - y ejercer sus derechos, además, que estén al alcance de todos en condiciones de igualdad (Gorjón Gómez y Steele Garza 2008).

Ya son varios los esfuerzos realizados para facilitar la accesibilidad a la justicia, por ejemplo: el Consejo europeo de tempere, octubre de 1999, en su punto 30 planteó la necesidad de mejorar la accesibilidad de la justicia en Europa, haciendo referencia a que los estados miembros deberían instaurar procedimientos extrajudiciales alternativos (Gordillo Santana 2007). Así mismo, en México el "Proyecto para la Mediación en México ABA-USAID" creó las estructuras necesarias para su implementación, aunadas a las diferentes reformas tanto federales como locales que establecieron la infraestructura necesaria para la ejecución de los MASC.

Debido a lo anterior, la mediación comunitaria debiera ser considerada una política socialque trabaje en conjunto con la vía jurisdiccional o administrativa, satisfaciendo en gran medida las exigencias de la sociedad respecto a la justicia, debido a que la mediación llega a los lugares que no puede el sistema judicial tradicional favoreciendo la transformación de la cultura del litigio por una cultura de paz.

\section{Diálogo}

El diálogo es probablemente la característica más evidente de los MASC, debido a que estos procedimientos hacen uso del mismo, como herramienta, para la búsqueda de soluciones.

La mediación es un método de solución pacífica de conflictos basado en el diálogo y que es eficaz por que permite que las personas implicadas asuman la responsabilidad de su conducta, el protagonismo de solución del conflicto, y recobren la sensación de paz y de equilibrio emocional existentes previos al inicio del conflicto (Ríos Martín, Pascual Rodríguez y Bibiano Guillén 2008). 
Este protagonismo de las partes en la gestión de su propio conflicto, genera en las mismas una gran confianza en la transparencia del sistema, al mantener en todo momento el control de un proceso de diálogo que se pone explícitamente en sus manos (García García 2003).

El objetivo de la mediación es reconstruir el puente comunicacional que ha sido fracturado por la aparición del conflicto. Es a través del diálogo que se fomenta la empatía, la solidaridad, cooperación, colaboración, el entendimiento, la capacidad de escucha y que permite el esclarecimiento de las necesidades e intereses de las partes, características que auxilian al aumento del cumplimiento del convenio realizado por ellas mismas.

La herramienta principal de la mediación es el diálogo, un diálogo por la paz, no con el esfuerzo de ganar, sino con el propósito de fomentar la empatía, la no violencia y la creatividad que potencie las competencias para superar el conflicto (Gorjón Gómez y Sáenz López 2009).

Es muy importante para la estabilidad política y la cohesión social, crear políticas de prevención de conflictos como la mediación, pacificando las relaciones antagónicas al excluir los elementos subjetivos y personales, instaurándose un respeto personal que permite el diálogo y el reconocimiento de la causa del adversario (Simmel 2010).

Así mismo, con la implementación de la mediación como política social, se estaría fomentando la participación activa de la sociedad en la resolución de sus propios conflictos, comprendiendo y asumiendo sus responsabilidades para el cambio y la mejora y no delegando esta función exclusivamente al Estado.

\section{Pacificación}

Generalmente cuando las partes acuden por primera vez a un procedimiento de mediación, asisten con la desconfianza habitual que genera el desconocimiento del procedimiento. La actitud adoptada por los mediados es defensiva, fundamentada por la cultura del litigio, que nos predispone a derrotar a nuestro "adversario" partiendo de una rígida e inflexible posición. Posteriormente, estas actitudes y posiciones van cambiando conforme avanza el procedimiento de mediación, y es a través de características como el diálogo, la tolerancia, la cooperación, colaboración, empatía, igualdad y la participación, que la sensación de hostilidad que tenían al principio, en la mayoría de los casos cambia por un sentimiento de paz.

Carme Boqué (Cultura de mediación y cambio social 2003) señala que la paz la construimos día a día, cada vez que afrontamos un conflicto de manera creativa, 
tomamos una decisión contando con el punto de vista de los demás, dialogamos, trabajamos cooperativamente, cultivamos nuestras relaciones interpersonales, aceptamos una diferencia, nos comprometemos con los valores humanos, etc. y la mediación es de gran ayuda para construir ese quehacer cotidiano.

Con la implementación de la mediación comunitaria como política pública social, se estaría poniendo en marcha un programa especializado para la prevención y gestión de los conflictos que conllevaría a la pacificación y cohesión de las sociedades.

\section{Rol activo en la construcción del convenio}

La elaboración consensuada del convenio por parte de los mediados es una característica de la mediación, que fomenta la autodeterminación y el protagonismo de las personas en conflicto (Boque Torremorell 2003).

En la mediación, a diferencia del juicio, las partes adquieren un papel protagónico donde son ellas las que deciden el curso y resultado del procedimiento, y tras una o varias sesiones, redactan de manera conjunta el convenio que contiene las soluciones a las que ellas han llegado para solucionar su controversia.

La mediación tiende a diluir las hostilidades al promover la cooperación entre las partes. Por el contrario, el litigio tiende a centrar las hostilidades y a hacer que la ira de los contendientes se intensifique hacia posiciones rígidamente polarizadas. El proceso jurisdiccional con su dependencia de los abogados como representantes de sus clientes, tiende a negar a las partes la oportunidad de asumir el control de su propia situación, y fortalece su dependencia en la autoridad externa (Folberg y Taylor 1996). En cambio la mediación, otorga la oportunidad a las partes de transformarse en protagonistas proactivos en el manejo de los conflictos (Fried Schnitman 2000).

La inclusión de prácticas orientadas a hacer participar a la población en la solución de sus conflictos como miembros de la sociedad, incide notoriamente en la mejora de su sociabilidad cotidiana (García-Longoria Serrano y Pastor Seller 2011).

El hecho de que sean las propias partes las que elaboran el convenio que ponga fin a su conflicto, hace que perciban la solución como algo propio y no como una decisión impuesta por un tercero. Por tal motivo, el acuerdo alcanzado es más aceptable y duradero que aquél impuesto por un tribunal (Fried Schnitman 2000).

Varios autores - Lucía García García, JayFolger y Alison Taylor, Ma. Carme BoquéTorremorell, Salvador Puntes, entre otros- concuerdan que el grado de cumplimiento voluntario de los acuerdos que se logran bajo el procedimiento de mediación, es mayor que las decisiones impuestas por los órganos jurisdiccionales, debi- 
do al sentimiento de compromiso y de responsabilidad las partes de cumplir lo propuesto por ellas.

La colaboración de las partes en la resolución de sus conflictos, es una de las características de la mediación que la dotan de eficacia a la hora de cumplimentar los acuerdos, en contraste con la nula participación de las partes en el proceso y en la resolución de sus conflictos en los procesos litigiosos.

En este marco de ideas, se debieran constituir políticas públicas sociales que potencien la participación ciudadana en la prevención y gestión de los conflictos que surgen en el seno de las sociedades, donde la autodeterminación y participación de las partes es fundamental. Salvador Puntes (La mediación social como actividad de promoción de la participación ciudadana y del ejercicio de los derechos sociales 2004) nos comenta que más allá de la participación de los mediados en la construcción de sus propios acuerdos, el cumplimiento eficiente de los mismos se debe al sentimiento de propiedad que se produce por efecto del mismo proceso de participación.

\section{ANÁLISIS DE RESULTADOS}

Los elementos del proceso de mediación anteriormente descritos, suponemos son los que más favorecen a la hora de implementar este método alternativo como política pública social.

Para poder dilucidar la hipótesis planteada, se decidió utilizar el instrumento cualitativo llamado entrevista a profundidad, el cual se aplicó a cuatro grupos que se denominaron política social, investigadores, mediadores y mediados, en los cuales encontramos a reconocidos profesionistas, teóricos y académicos expertos en los temas de política social y mediación, así como también, a los partícipes en la misma. La justificación de haber seleccionado a los entrevistados fue por una parte el conocimiento en la materia y por la otra, las experiencias vividas en las sesiones de mediación.

Una vez finalizadas las entrevistas, los datos arrojados fueron analizados desde la perspectiva de cada uno de los grupos entrevistados, para posteriormente conocer cuáles son los elementos de la mediación que más favorecen su aplicación gubernamental como política pública social.

El primer grupo de entrevistados a analizar, corresponde al grupo denominado política social, el cual considera que los elementos de la mediación que más favorecen a su aplicación gubernamental como política pública social son: (gráfica 1) 
GrÁFICO 1

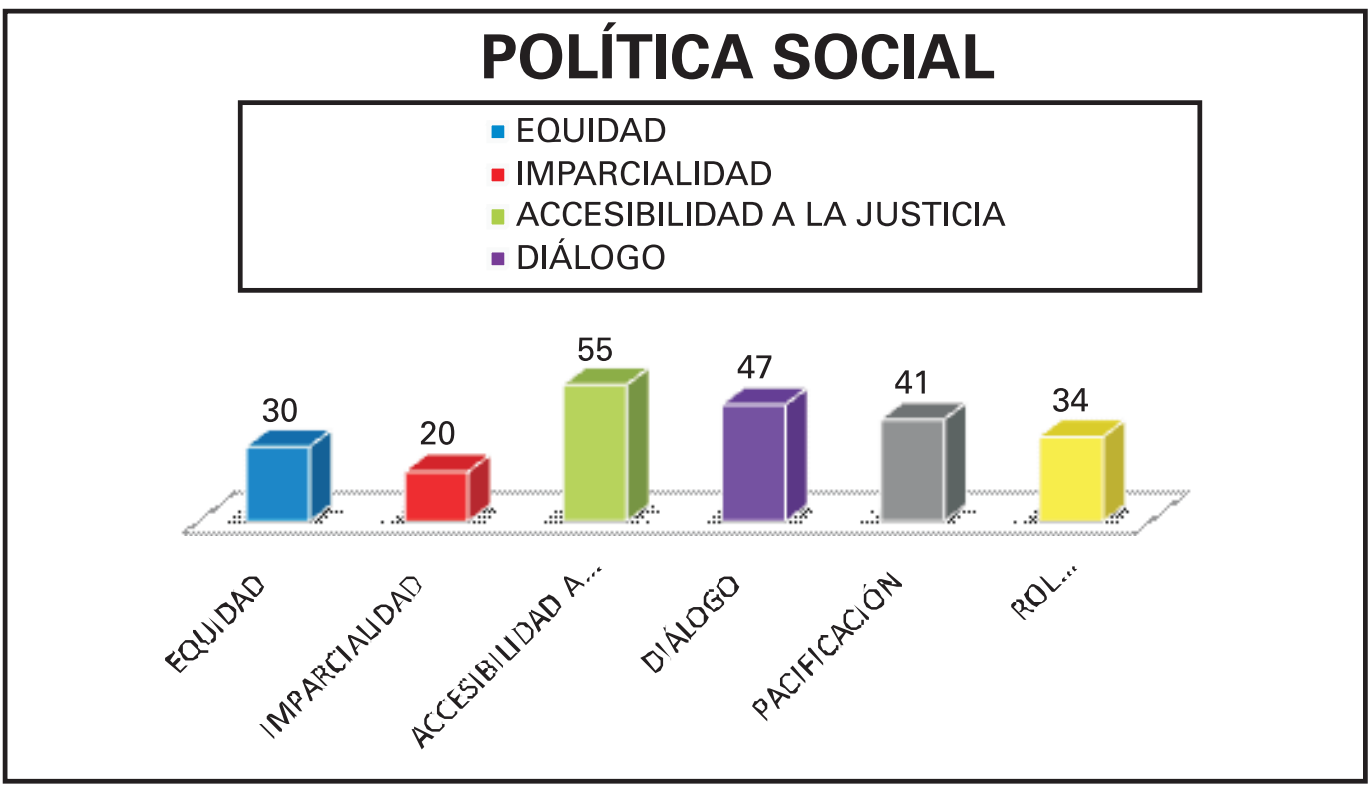

- La accesibilidad a la justicia

- El diálogo

- Pacificación

La variable que obtuvo más menciones durante las entrevistas fue la referida a la accesibilidad a la justicia, misma que se convierte, a consideración de los entrevistados, en el elemento del proceso de mediación que más sobresale a la hora de pretender implementarla como política pública social.

La accesibilidad a la justicia es una característica de la mediación que permite a los ciudadanos solventar una amplia gama de conflictos, sin tener la necesidad de recurrir a los complejos y dilatados procedimientos judiciales, en los que, un juez va a resolver la disputa a través de una sentencia, lo que conlleva a la contratación de profesionales capacitados en los procedimientos jurídicos y a los altos costes tanto económicos como emocionales que genera el conflicto. De tal manera, que al ser la mediación un procedimiento eficaz en la resolución de los conflictos, que se caracteriza por el diálogo y en la participación activa de los implicados en el conflicto, lo que permite acercarse a los principios de equidad y justicia. Por tanto, podríamos considerar la mediación como un procedimiento que facilita el acceso a la justicia, a la vez que aporta cohesión social.

El segundo elemento del proceso de mediación que más frecuencias tuvo en las respuestas de los entrevistados de este grupo, fue el del diálogo, muy probable- 
mente por ser éste imprescindible para lograr el consenso de todas las partes implicadas en el conflicto y alcanzar soluciones que satisfagan sus necesidades.

Desde el ámbito de las políticas sociales, los conflictos donde falta la voz y la capacidad para el diálogo, conlleva riesgos y tensiones sociales que pueden generar violencia que pongan en peligro la integridad y cohesión de las sociedades.

Por tal motivo, creemos que desde la perspectiva de este grupo de entrevistados, la importancia de contar con políticas sociales que se basen en el diálogo es fundamental y es por ello que estamos convencidos que la mediación comunitaria debiera ser considerada una política social que ayude a la prevención y manejo de los conflictos que surjan en el seno de las sociedades, fomentando la participación ciudadana a través del diálogo así como fortalecer su tejido social, creando vínculos y estructuras comunitarias más solidas que permitan gestionar de manera positiva sus propios conflictos.

En relación con lo anterior, Boqué (Cultura de mediación y cambio social 2003) señala que la mediación pude ser un empujón hacia la cohesión social, puesto que al incluir a los distintos participantes en un conflicto, se promueve la comprensión, se defiende la pluralidad y se fomenta la libre toma de decisiones y compromisos, contribuyendo a la participación democrática.

De tal manera que estableciendo la mediación como una política pública social que permita la participación activa de la sociedad en la resolución de sus conflictos, se generarían sentimientos de control, sosiego y tranquilidad, mismos que podríamos englobarlos en lo que comúnmente se conoce como pacificación social. Precisamente éste es el tercer elemento del proceso de mediación que los entrevistados consideran más relevante a la hora de querer implementarla como política social.

Interpretamos que la pacificación se convierte en un aspecto destacable desde la óptica de los entrevistados, debido probablemente a que uno de los objetivos de las políticas sociales consiste en cuidar y mantener la unidad de las sociedades frente a los peligros de disolución y destrucción, de los que se encuentra amenazada por las relaciones sociales de unos grupos con otros (Rodríguez 1979), por tanto, es menester del Estado y los otros órganos públicos tratar de asegurar la paz social(Rodríguez 1979).

El siguiente grupo de entrevistados a analizar corresponde al grupo denominado investigadores, los cuales consideran que los elementos de la mediación que más favorecen su aplicación gubernamental como política pública social son: (gráfica 2) 


\section{GrÁFICO 2}

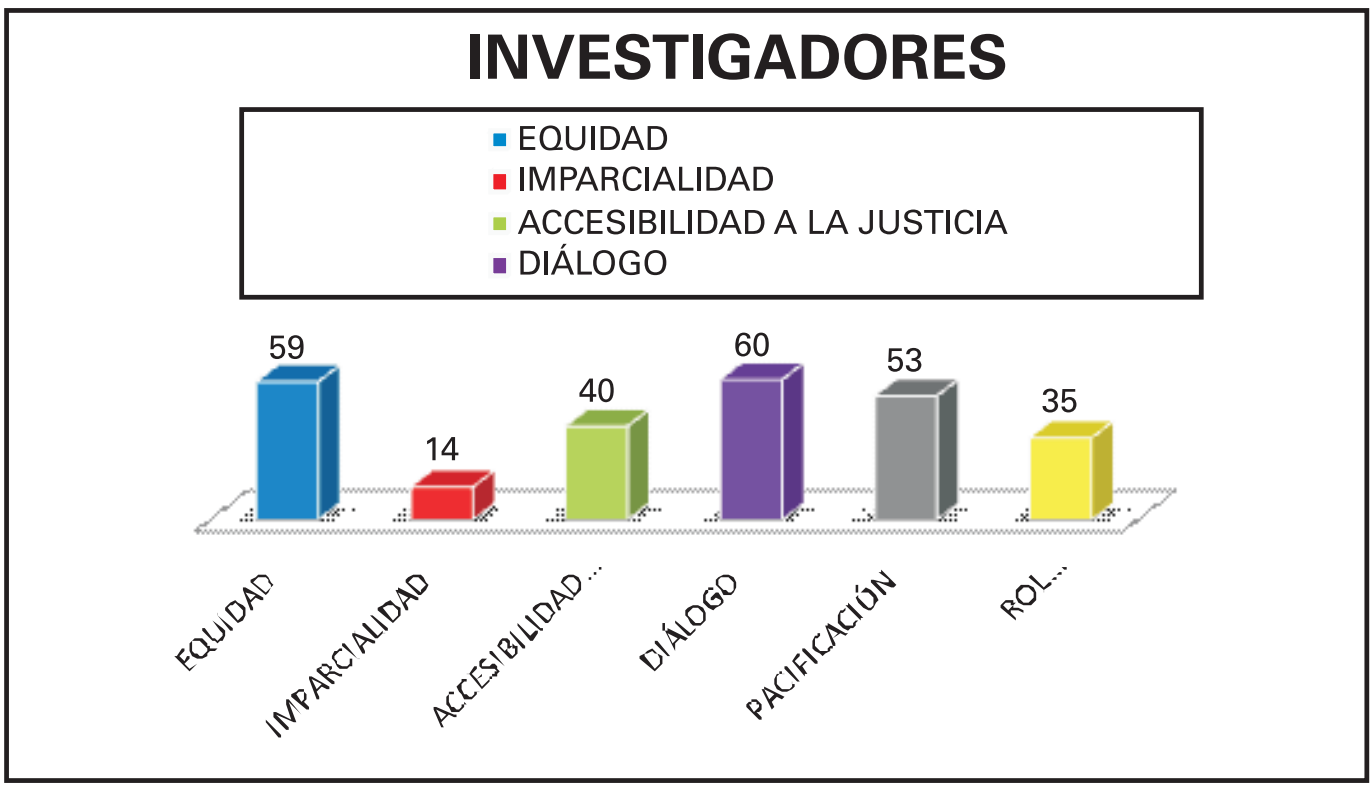

- El diálogo

- La equidad

- La pacificación

- La accesibilidad a la justicia

Según los entrevistados el diálogo y la equidad son los elementos del proceso de mediación que más favorecen a su implementación como política social, muy probablemente por considerar que al resolver las partes sus propios conflictos por medio de procedimientos no adversariales basados en el diálogo, las resoluciones emanadas de los mismos son consideradas por las partes como más equitativas.

Así mismo, las características del proceso de mediación permiten a las partes enfrentadas, resolver sus conflictos en un espacio donde se procura el equilibrio y el respeto entre las mismas, un espacio donde trabajan colaborativamente en la resolución de sus conflictos, aceptando las decisiones, puntos de vista y diferencias de los demás, fortaleciendo sus relaciones interpersonales.

Gestionando positivamente sus conflictos, las partes se sienten más comprometidas con los resultados obtenidos, propiciando un cumplimiento mayor de lo pactado que las resoluciones en las cuales no son partícipes directos. Con la aplicación de procedimientos de resolución pacífica de conflictos como la mediación, se crean espacios donde la paz aflora, en la medida de que las partes enfrentadas son capa- 
ces de transformar los conflictos en cooperación, de forma positiva y creadora, reconociendo a sus oponentes utilizando como método del diálogo (Fisas 2006).

Otro de los elementos del proceso de mediación que favorece a su implementación como política social según los entrevistados, es el de la pacificación. Como anteriormente se ha mencionado, uno de los resultados de la aplicación de métodos alternativos de solución de conflictos, en especial la mediación, es que los participantes experimentan sensaciones de tranquilidad cuando ellos mismos asumen el control del proceso y las soluciones a las que arriban, son soluciones que emanan de ellos mismos.

El hecho que la sociedad misma sea la que por medio del diálogo aborde y solucione sus conflictos, proporciona un cambio de paradigma en la manera de afrontar a los conflictos, caracterizado por la cooperación, colaboración, empatía, solidaridad, etc., principios que conforman una cultura de paz. En cambio, si los conflictos no son abordados adecuadamente, surgen sentimientos de injusticia que a la postre generan otros sentimientos como la humillación, el odio, la venganza y la desconfianza, que germinan escenarios donde difícilmente se instaure esa cultura de paz que anteriormente mencionábamos.

Otro de los beneficios de este nuevo paradigma, es el bagaje pedagógico que experimentan los participantes en la mediación, es decir, provee a las partes de herramientas para manejar creativa y positivamente posibles conflictos futuros, fomentando la pacificación.

Por último, la facilitación al acceso a la justicia es a consideración de los entrevistados otro de los elementos del proceso de mediación que favorece a su implementación gubernamental como política pública social.

Los entrevistados concuerdan en que la aplicación de la mediación proporciona opciones diferentes a los procedimientos judiciales, en los cuales las soluciones se obtienen de una forma más rápida, eficaz y de menor coste emocional y económico.

De igual manera, la utilización de la mediación proporciona alivio a la vez de complementar a las estructuras judiciales, por resolver en plazos más cortos, los conflictos que anteriormente saturaban la capacidad resolutoria de los tribunales. Por tal motivo, se considera que el uso de la mediación fortalece el acceso a la justicia otorgando desde la perspectiva de los participantes, resoluciones más justas a la vez que se mejora el sistema de impartición de justicia.

Otra de las características de la mediación que facilita el acceso a la justicia es sin duda su capacidad de adaptabilidad al caso concreto, por tal motivo, la mediación llega a lugares a los que no tiene acceso el sistema judicial, al ser éste de aplicación general. 
Así mismo, cuando las partes - conforme a su propia naturaleza y conveniencia y para establecer un acuerdo- determinan sus obligaciones y derechos ante la existencia de un conflicto, estaríamos en presencia de una opción real para alcanzar la justicia (Gorjón Gómez y Steele Garza 2008).

El siguiente grupo de entrevistados a analizar corresponde al grupo denominado mediadores, los cuales consideran que los elementos de la mediación que más favorecen su aplicación gubernamental como política pública social son: (gráfica 3)

\section{GrÁFICO 3}

\section{MEDIADORES}

- EQUIDAD

- IMPARCIALIDAD

- ACCESIBILIDAD A LA JUSTICIA

- DIÁLOGO
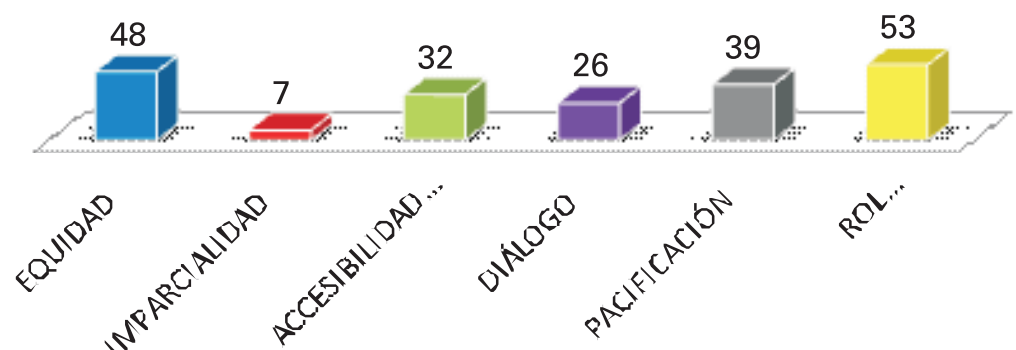

- El rol activo en la construcción de los convenios

- La equidad

- La pacificación

Los mediadores son profesionales en la conducción de disputas, que aplican distintas herramientas con la intención de guiar a las partes en un proceso comunicacional donde colaborarán entre sí en la búsqueda de soluciones que pongan fin a su controversia.

Precisamente, la participación activa de las partes en la resolución de sus conflictos es uno de los aspectos que más énfasis ponen los mediadores a la hora de describir el proceso de mediación, por tanto, este aspecto se convierte en la variable que más menciones obtuvo por parte del grupo de entrevistados. 
El rol activo de las partes en la construcción del convenio, se refiere básicamente, a que son ellas mismas las protagonistas en el manejo y resolución de sus conflictos, confeccionando y seleccionando las opciones que han ido planteando a lo largo del procedimiento de mediación, aglutinándolas en el documento que finiquite la disputa.

Este papel activo de las partes, proporciona sentimientos de responsabilidad, pacificación y justicia, que permiten considerar al convenio que pone fin a su controversia como más justo y que es de su propiedad, elevando considerablemente el grado de cumplimiento del mismo.

En este contexto, Dora Fried Schnitman (Nuevos paradigmas en la resolución de conflictos. Prespectivas y prácticas. 2000) Apunta que el acuerdo alcanzado por la partes es más aceptable y duradero que aquél impuesto por un tribunal.

La ciudadanía del siglo XXI es cada vez exigente y demandante, le gusta decidir y participar en las decisiones que inciden directamente en su comunidad (Sáenz López y Vera Carrera 2011). Implementando la mediación comunitaria como política pública social, se potenciaría la participación activa de la sociedad en la búsqueda de soluciones los conflictos a los que se enfrenten, poniendo de relieve que la posibilidad de tomar las propias decisiones en base a demandas legitimadas consensuadamente aumenta el umbral de responsabilización hacia los conflictos (Boque Torremorell 2003).

Otra de las variables que más menciones tuvo fue la de equidad. La mediación permite que las partes enfrentadas realicen negociaciones con la intención de solucionar por ellas mismas sus conflictos, buscando desde su perspectiva la solución más justa y equitativa. Al satisfacer adecuadamente las necesidades de las personas, se estaría fomentando la pacificación de las relaciones conflictivas, es decir a la paz (Güell, Gorjón Gómez y Sánchez Vázquez 2011).

Para los mediadores es fundamental la existencia de la equidad en los procesos de mediación, debido a que sin la existencia de esta característica sería imposible alcanzar acuerdos justos, imparciales, ecuánimes y neutrales, haciendo improbable la satisfacción real y efectiva de las necesidades e intereses de las partes. Así mismo, al no existir una equidistancia, una igualdad y un equilibrio entre las mismas, optarían por la vía jurisdiccional para intentar solucionar sus conflictos, coartando la participación activa de la ciudadanía en la resolución de sus conflictos lo cual retardaría su solución y los colocaría nuevamente en el escenario de la actual crisis de impartición de la justicia.

Para lograr la equidad en los procesos de mediación, los mediadores procurarán que las partes se sientan legitimadas y reconozcan sus derechos, fomentando un espacio donde se puedan expresar libremente y valoren las propuestas de los 
demás dentro de un proceso de igualdad que les beneficie en la búsqueda de soluciones a sus conflictos.

La equidad se convierte en un elemento primordial y casi imprescindible para lograr la pacificación (Martín 2011) de los conflictos, elemento del proceso de mediación que a consideración del grupo de entrevistados, favorecería a la implementación gubernamental de la mediación comunitaria como política pública social.

La pacificación de las relaciones conflictivas se debe según la perspectiva de los mediadores, a que las partes adquieren herramientas que les facilitarán la gestión positiva de futuros conflictos disminuyendo considerablemente los niveles de angustia, estrés, miedo y tensión, emociones que incitan la aparición de la violencia.

El siguiente grupo de entrevistados a analizar corresponde al grupo denominado mediados, los cuales consideran que los elementos de la mediación comunitaria que más favorecen su aplicación gubernamental como política pública social son: (gráfica 4)

\section{GRÁFICO 4}

\section{MEDIADOS}
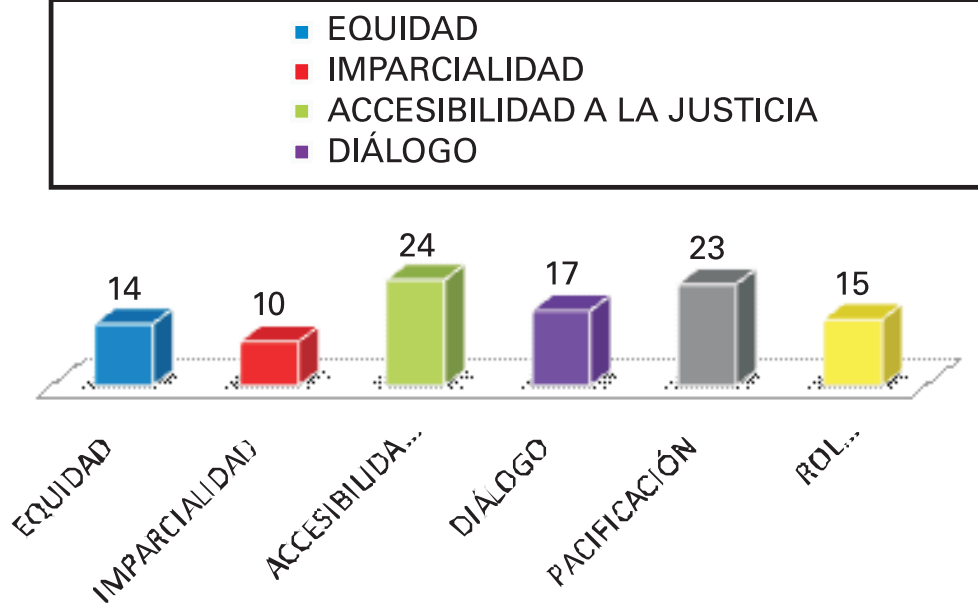

- La accesibilidad a la justicia

- La pacificación

- El diálogo

La accesibilidad de la justicia es para los entrevistados el elemento que más menciones ha obtenido, debido muy probablemente a que los mediados se sienten satis- 
fechos con los acuerdos alcanzados, mismos que son elaborados por ellos mismos cumpliendo con sus intereses y necesidades reales.

De igual manera, influyen notablemente en los entrevistados varios aspectos del proceso de mediación que reiteran la variable analizada. Estas características de la mediación son: la facilidad en la resolución de conflictos, la flexibilidad e informalidad del procedimiento y la rapidez del mismo.

Cuando surge un conflicto y las partes enfrentadas deciden optar por la mediación como método resolutivo, obtienen un mayor protagonismo en la gestión del mismo, lo que les beneficiará en la búsqueda de soluciones que pongan fin a su conflicto. Al generar distintas opciones, las partes tendrán más posibilidades de seleccionar las que más se adecuen a sus necesidades, la ausencia de tantas formalidades en el proceso y de la cualidad del mismo para ajustarse a los requerimientos de las partes, permite considerar a la mediación como un proceso más humano, sencillo y amigable, que propicia la solución rápida y positiva de sus conflictos.

Así mismo, una vez analizadas las respuestas de los entrevistados, se pudo constatar que existe otra característica del proceso de mediación que no fue tomada en consideración por nuestra parte como variable en este estudio y que se encuentra íntimamente relacionada con la variable de la accesibilidad a la justicia. La característica que hacemos alusión es el aspecto gratuito y/o económico de este procedimiento.

El ahorro económico y emocional que experimentan las personas que han participado en un procedimiento de mediación, viene a convertirse - según este grupo de entrevistados - en un aspecto muy relevante; normalmente, los mediados han tenido conocimiento de este procedimiento después de haber asistido a algún proceso judicial, - en el que, su participación se ve disminuida al mínimo por la existencia de formalismos que dotan a este proceso de un grado de dificultad que obliga a la contratación de profesionales capacitados para la conducción de litigios, además, si aunamos la excesiva carga de asuntos que llevan los tribunales, la resolución a su conflicto tarda en llegar ocasionándoles mayor desgaste emocional- o después de tratar sin éxito de solucionar el conflicto por ellos mismos.

Posterior a su participación en la mediación, los entrevistados la consideran un procedimiento confiable y capaz para solventar sus diferencias en un espacio donde son escuchados y comprendidos, donde la frustración, la ira, la impotencia, la desconfianza y la sensación de pérdida, son cambiadas por sentimientos de control, calma, tolerancia, igualdad, tranquilidad y paz, cuando se logra, los mediados sienten que se les ha hecho justicia.

Las partes obtienen como resultado de su participación en el proceso de mediación un acuerdo que pone fin a su controversia, mismo que se obtuvo con la parti- 
cipación activa y colaboración de las mismas, así como el bagaje de nuevas herramientas para la gestión y trata positiva de futuros conflictos.

El acuerdo alcanzado les permite convivir con armonía y tranquilidad, al sentirse liberados de las ataduras de los conflictos; a menudo expresan frases como que se han quitado una losa de encima o una gran carga.

Esos sentimientos se engloban en la segunda variable con más menciones por parte de los entrevistados, es decir, la pacificación.

La mediación se convierte en una vía para alcanzar la pacificación, al fomentar la cooperación, la empatía, la solidaridad, la participación activa de la sociedad, el diálogo, la igualdad y el respeto de los derechos fundamentales del hombre; elementos integradores de una cultura de paz. La implementación de la mediación comunitaria como política social, vendría a satisfacer las deficiencias en la impartición de la justicia, disminuyendo los niveles de violencia en las relaciones conflictivas así como convertirse en instrumento de cohesión social.

Y por último, los entrevistados consideran que el diálogo es una de las características del proceso de mediación que favorecerían a su implementación gubernamental como política social.

El grupo entrevistado ha manifestado sentirse satisfecho con el procedimiento de mediación debido a que son escuchados y comprendidos, de igual manera, las partes al convertirse en las protagonistas en la búsqueda de soluciones a su conflicto, adquieren confianza en el procedimiento y se sienten motivados a conversar sus problemas manifestando abiertamente sus emociones, lo que les permite mostrarse empáticos con su contraparte, facilitando la búsqueda de opciones que pongan fin a su controversia.

La mediación es un procedimiento sencillo, informal y práctico que promueve la comunicación como medio para que las partes enfrentadas puedan llegar a solucionar su conflicto a través de la empatía, la solidaridad, la cooperación, la colaboración, el entendimiento y la capacidad de escucha permitiendo el esclarecimiento de sus necesidades e intereses, características sine qua non para el cumplimiento del convenio realizado por ellas mismas.

La presencia del diálogo es fundamental para la economía de tiempo que ofrece la mediación; la ausencia del mismo, dificultaría enormemente la resolución temprana y eficaz de los conflictos, las partes seguirían enquistadas y muy posicionadas, además de no sentirse protagonistas en la resolución de su conflicto. Por tal motivo, se constata de la necesidad de contar con programas que potencien la participación ciudadana en la resolución de sus conflictos, a través del diálogo. 


\section{GrÁFICO 5}

\section{ELEMENTOS DE LA MEDIACIÓN QUE FAVORECEN A SU IMPLEMENTACIÓN COMO POLÍTICA SOCIAL.}

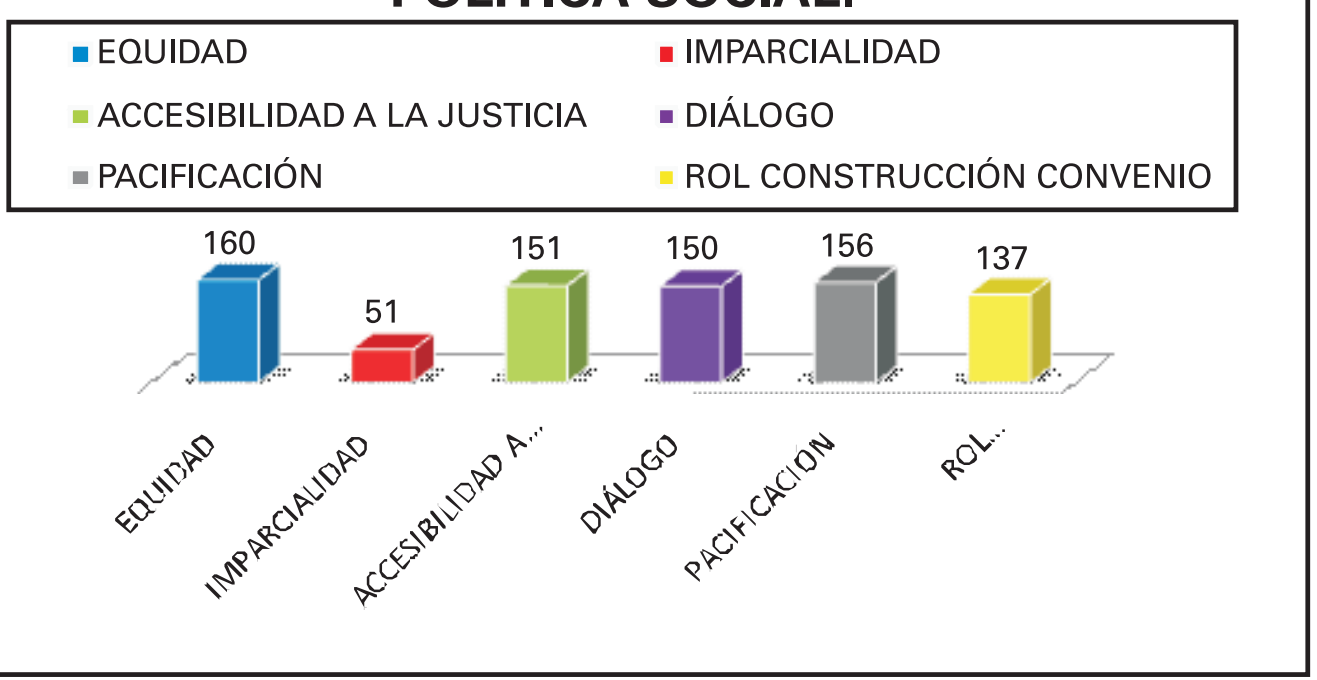

\section{CONCLUSIONES}

Para poder determinar cuáles de las variables de ésta investigación, son las que más favorecen a la implementación de la mediación comunitaria como política pública social, fue necesario agrupar los resultados de cada uno de los grupos estudiados.

Los datos arrojados por la aplicación de nuestro instrumento constataron que según los entrevistados las variables que más sobresalen son:

- La equidad,

- La pacificación,

- El acceso a la justicia, y

- El diálogo.

La equidad viene a convertirse en uno de los elementos del proceso de mediación que más favorecen a su implementación como política pública social, debido a que pretende que tanto en el proceso como las resoluciones emanadas del mismo, sean lo más justas e igualitarias posibles. 
Los que han participado en un procedimiento de mediación, indistintamente si han llegado o no a un acuerdo, lo consideran un método resolutivo de conflictos justo e igualitario, en donde pueden expresar libremente su punto de vista y que serán escuchados sin ningún prejuicio ni preferencia respecto a su contraparte. Además, si arriban aun acuerdo, el mismo satisface sus necesidades e intereses reales y no sus posiciones, por lo que consideran que se les ha hecho justicia, es aquí donde el principio de la equidad se encuentra íntimamente ligado al término de la justicia expresado por Ulpiano, quién manifestaba que la justicia significa darle a cada quien lo que le pertenece. Al respecto, Gorjón y Steele (Métodos Alternativos de Solución de Conflictos 2008) mencionan que una de las principales características de los métodos alternativos de solución de conflictos, es que nos acercan más a la equidad y la justicia que la vía judicial en la solución de conflictos. Esto hace pensar que la justicia es más equitativa cuando las partes resuelven sus diferencias con base a un procedimiento no adversarial.

La presencia de la equidad en el procedimiento de mediación favorece al diálogo y potencia la participación de la ciudadanía en la búsqueda de soluciones a sus conflictos. Para que ésta aparezca y se mantenga a lo largo de las sesiones, es necesario que el mediador desempeñe su labor de una manera íntegra e imparcial, así mismo, debe lograr equilibrar el poder entre las partes, incentivarlas a que dialoguen y se escuchen, comprendan y respeten entre ellos.

Otro de los elementos del proceso de mediación que según los entrevistados debe ser tomado en cuenta para considerarla como una política social, es la pacificación.

Cada vez que surge un conflicto, sea del tipo que sea, si no es gestionado de forma adecuada, se estanca y paraliza los procesos de negociación, fragmenta la comunicación y encoleriza las relaciones elevando los índices de agresividad dificultando su solución. En cambio, cuando los conflictos son gestionados positivamente, aflora la comunicación, el respeto, las opciones de solución y la pacificación de las relaciones.

En relación con lo anterior, Johan Galtung (Fisas 2006) menciona que en la medida que somos capaces de transformar los conflictos en cooperación, de forma positiva y creadora, reconociendo a los oponentes y utilizando el método del diálogo, estaríamos trabajando a favor de la paz.

La mediación otorga esa posibilidad de transformar positivamente los conflictos, brindando un espacio donde son reconocidos los derechos de los oponentes, utilizando el diálogo como medio para alcanzar acuerdos, potenciando la participación y cooperación de los contendientes en la búsqueda de opciones que satisfagan sus necesidades.

Por tal motivo, es necesaria la existencia de programas gubernamentales que consideren a la mediación comunitaria como política social, para que los ciudadanos 
puedan gestionar positivamente sus conflictos y satisfacer sus intereses, ayudando con ello a la implementación de la cultura de paz.

En este sentido, la mediación contribuye a la pacificación y a la justicia social, al resolver asertivamente los conflictos contando con la participación activa de sus protagonistas, desarrollando aptitudes para el diálogo, la negociación, la formación de consenso y la solución pacífica de sus controversias, características que constituyen una cultura de paz.

Otro de los elementos del proceso de mediación que más favorecen a su implementación como política social es la accesibilidad a la justicia, esto gracias a sus características que le permiten acceder a una gran cantidad de conflictos.

El acceso a la justicia es un derecho fundamental que se encuentra en todas las constituciones democráticas del mundo, en el caso de la Constitución Española de 1978 lo encontramos en el artículo 24, fracción primera, y en el caso de la Constitución Política de los Estados Unidos Mexicanos de 1917 encontramos este derecho en el artículo 17.

Sin embargo, es un hecho probado que la ciudadanía refleja un gran descontento en la administración judicial debido a varios defectos. Los litigios ante los tribunales se multiplican, los procedimientos tienden a alargarse y los gastos ocasionados por dichos procedimientos aumentan. La cantidad, la complejidad y el carácter oscuro o demasiado técnico de los textos legislativos contribuyen a dificultar el acceso a la justicia, siendo el de la dilación en la resolución de los procedimientos uno de los aspectos más preocupantes (Gonzalo Quiroga 2011).

Debido a lo anterior, se constata la necesidad de modernizar los sistemas judiciales, dotándolos de mayor dinamismo, efectividad y eficiencia a la hora de solucionar los conflictos surgidos de las sociedades actuales.

España y México se encuentran ya metidos de lleno en la modernización de sus sistemas judiciales, y han observado que la inclusión de los MASC en sus legislaciones viene a dinamizar la administración de justicia dotándola de una mayor agilidad, flexibilidad, rapidez y menor coste económico. Por ejemplo, el artículo 17 de la Constitución Política de los Estados Unidos Mexicanos, en el cual encontramos el derecho que tiene toda persona para que se le administre justicia de manera pronta y expedita, tuvo que ser reformado para conferirle ese dinamismo a que nos referimos y poder garantizar el acceso efectivo a la justicia. Debido a que la gran cantidad de asuntos que son llevados a los tribunales y a lo complejo de los procedimientos judiciales, no permitía la pronta resolución de los conflictos. Fue entonces que los legisladores sintieron la necesidad de anexar en el artículo en cuestión, la incorporación de los MASC para que sean utilizados en aquellos asuntos en los cuales llegan a ser de gran utilidad para su solución, dejando a conocimiento de los 
tribunales aquellos asuntos en los cuales no se recomienda la utilización de algún MASC.

Este elemento facilitador de la justicia encontrado en la mediación, viene a convertirse en un importante aliado para combatir el rezago en la impartición de la justicia. Profesionales en el ámbito de la política social, consideran oportuno contar con programas gubernamentales de resolución de conflictos que acerquen la justicia a la sociedad y sea ella la protagonista en encontrar las soluciones a sus conflictos, dejando de depender de la tradicional impartición de justicia que caracteriza el estado paternalista en el que vivimos, lo que fortalecerá a las sociedades en su estructura y tejido social.

Por lo que consideran sumamente importante que la modernización de los sistemas judiciales se encuentre incluida en los planes estratégicos de políticas públicas y de economía sostenible de todos los Estados. Porque garantizar el acceso a la justicia, se convierte en un elemento dinamizador de las economías, al reducir los costes, desbloquear los activos y garantizar una mayor seguridad jurídica, generando una mayor confianza en la economía y en las decisiones empresariales, internas e internacionales, al establecer un marco de previsibilidad (Gonzalo Quiroga 2011).

Igualmente los participantes en los procedimientos de mediación, consideran esta cualidad de la mediación - la accesibilidad a la justicia - como uno de los elementos más importantes a la hora de valorar este procedimiento resolutivo de conflictos, debido a su gratuidad y/o a su baja onerosidad, lo que les permite acceder a resolver sus conflictos sin perjuicio de su condición económica o social.

Así mismo, la sencillez y pragmatismo de este método permite una buena comprensión y el ejercicio del mismo por parte de los usuarios, reduciendo considerablemente el tiempo en la resolución de los conflictos en comparación con el litigio judicial.

Y por último, la presencia del diálogo en los procedimientos de mediación es otros de los elementos que más influyen en su implementación como política pública social a consideración de los entrevistados.

Es a través del diálogo que se fomenta la empatía, la solidaridad, cooperación, colaboración, el entendimiento y la capacidad de escucha, condiciones esenciales para la superación de los conflictos y a la vez permiten el esclarecimiento de las necesidades e intereses de las partes, aumentando las posibilidades en el cumplimiento del acuerdo alcanzado por ellas mismas.

El diálogo es uno de los pilares fundamentales de los MASC, que permite la gestión positiva de los conflictos, transformándolos en ideas, cooperación, empatía, solidaridad y comprensión de la diversidad de opiniones, logrando la integración, la 
creatividad, la participación y el consenso de los participantes, características esenciales para la construcción de una cultura de paz.

La mediación es un método de solución pacífica de conflictos que se basa en el diálogo y que es eficaz por que permite, entre otros aspectos, que las personas implicadas asuman la responsabilidad de su conducta, el protagonismo de solución del conflicto, y recobren la sensación de paz y de equilibrio emocional existentes previos al inicio del conflicto (Ríos Martín, Pascual Rodríguez y Bibiano Guillén 2008).

Al implementar la mediación comunitaria como política pública social, se estaría contribuyendo a la formación de una cultura cívica con actitudes basadas en la participación, la solidaridad y el respeto mutuo.

Así mismo, se estarían creando las bases para que todo conflicto que surja en el seno de las sociedades, pueda ser resuelto con una participación ciudadana más efectiva y a través del diálogo, encontrando soluciones satisfactorias tanto para el gobierno o quien ostente el poder en determinado momento y la ciudadanía, misma que reclama soluciones efectivas, rápidas, económicas y justas, a todos sus conflictos (Sáenz López y Vera Carrera 2011).

La implementación de la mediación comunitaria como política social aplicada al fortalecimiento de la cultura de paz en México y España, viene a convertirse en un esfuerzo más, para la instauración de una cultura donde se prime el diálogo, se promueva la transformación pacífica de los conflictos que surjan en el seno de las sociedades, se potencie la participación y responsabilización de la ciudadanía.

\section{BIBLIOGRAFÍA}

Baruch Bush, Robert A., y Joseph P. Folger. La promesa de la mediación. Cómo afrontar el conflicto a través del fortalecimiento propio y el reconocimiento de los otros. Buenos Aires: Granica, 1996.

Boque Torremorell, María Carme. Cultura de mediación y cambio social. Barcelona: Gedisa, 2003.

Esping-Andersen, Gøsta. "Prólogo." En Política social. Una introducción, de Teresa Montagut, 10. Barcelona: Ariel, 2008.

Fisas, Vicenç. Cultura de paz y gestión de conflictos. Barcelona: Icaria Antrazyt-UNESCO, 2006.

Folberg, Jay, y Alison Taylor. Mediación, resolución de conflictos sin litigio. México: Limusa, 1996.

Fried Schnitman, Dora. Nuevos paradigmas en la resolución de conflictos. Prespectivas y prácticas. Buenos Aires: Granica, 2000.

García García, Lucía. Mediación familiar. Prevención y alternativa al litigio en los conflictos familiares. Madrid: Dykinson, 2003. 
García-Longoria Serrano, María Paz, y Enrique. Pastor Seller. “La negociación mediadora en conflictos sociales." En Métodos Alternos de Solución de Conflictos. Herramientas de Paz y modernización de la justicia., de Gonzalo Quiroga Martha y Gorjón Gómez Francisco Javier., 167-179. Madrid: Dykinson, 2011.

Gonzalo Quiroga, Marta. "Métodos Alternos: una justicia más progresista y universalizada." En Métodos Alternos de Solución de Conflictos. Herramientas de paz y modernización de la justicia, de Marta Gonzalo Quiroga y Francisco Javier Gorjón Gómez, 41-61. Madrid: Dykinson, 2011.

Gordillo Santana, Luis. La justicia restaurativa y la mediación penal. Madrid: Iustel, 2007. Gorjón Gómez, Francisco Javier, y José Guadalupe Steele Garza. Métodos Alternativos de Solución de Conflictos. México: Oxford University Press, 2008.

Gorjón Gómez, Francisco Javier, y Karla Annett Cynthia Sáenz López. Métodos Alternos de Solución de Controversias. Enfoque eduactivo por competencias. México: Patria, 2009.

Güell, Leena, Francisco Javier Gorjón Gómez, y Rafael Sánchez Vázquez. “Los Métodos Alternos de Solución de Controversias como Herramientas de Paz." En Métodos Alternos de Solución de Conflictos. Herramientas de paz y modernización de la justicia, de Marta Gonzalo Quiroga y Francisco Javier Gorjón Gómez, 34. Madrid: Dykinson, 2011.

J., Taylor S., y R. Bogdan. Introducción a los métodos cualitativos de investigación. Barcelona: Paidós, 1984.

Lapasió Campos, Lola, y Ramón Marqués Esther. "La mediación: historia y modelos." En Mediación familiar. Conflicto: técnicas, método y recursos., de Miguel Ángel Soria, Carlos Villagrasa y Inma Armadans. Barcelona: Bosch, 2008.

Martín, Miguel Ángel. "IANCA." Instituto Argentino de Negociación, Conciliación y Arbitraje. 18 de Mayo de 2011. http://ianca.com.ar/2011/05/18/equidad-en-las-interrelaciones/ (último acceso: 14 de Septiembre de 2012).

Molina Cano, Jerónimo. Epítome de la Política social. Murcia: Isabor, 2007.

Montagut, Teresa. Política Social. Una introducción. Barcelona: Ariel, 2008.

Moreno Navarro, Gloria. Teoría del Derecho. México: McGraw-Hill, 1998.

Ortiz, Isabel. Guías de Orientación de Políticas Públicas. Estrategias Nacionales de Desarrollo, Nueva York: UN DESA, 2007, 1-75.

Patiño Reyes, Alberto. "Algunas consideraciones sobre la importancia de la imparcialidad cómo virtud suprema del juez." Revista electónica de Promoción de la Cultura y la Educación Superior del Bajío, 2007.

Puntes, Salvador. "La mediación social como actividad de promoción de la participación ciudadana y del ejercicio de los derechos sociales." Diputacio de Barcelona, 2004.

Real Academia Española. Diccionario de la Real Academia Española. www.rae.es (último acceso: 27 de Agosto de 2012).

Ríos Martín, Julián Carlos, Esther Pascual Rodríguez, y Alfonso. Bibiano Guillén. La mediación penal y penitenciaría. Madrid: COLEX, 2008.

Rodríguez, Federico. Introducción en la política social. Madrid: Civitas, 1979.

Ruiz Sánchez, Carlos. Manual para la elaboración de políticas públicas. México: Plaza y Valdés, 2002.

Sáenz López, Karla A. C., y Jessica M. Vera Carrera. “La negociación en el Contexto de Actividad Política de la Sociedad Civil." En Métodos Alternos de Solución de Conflictos. 
Herramientas de paz y modernización de la justicia, de Martha Gonzalo Quiroga y Francisco Javier Gorjón Gómez, 149-166. Madrid: Dykinson, 2011.

Simmel, Georg. El conflicto. Sociología del antagonismo. Madrid: Sequitur, 2010.

Six, Jean-François. "Le temps des médiateurs." En Cultura de mediación y cambio social, de María Carme Boque Torremorell. España: Gedisa, 2003.

Suares, Marines. Mediación. Conducción de disputas, comunicación y técnicas. Buenos Aires: Paidós, 2002. 


\section{comunitania}

REVISTA INTERNACIONAL DE TRABAJO SOCIAL Y CIENCIAS SOCIALES

REVISTA INTERNACIONAL DE TRABAJO SOCIAL Y CIENCIAS SOCIALES
INTERNATIONAL. JOURNAL OF SOCIAL WORK AND SOCIAL SCIENCES

\section{ARTICULOS/ARTICLES}

Estado de bienestar e inversión social en Europa / Welfare State and Social Invesment in Europe

Eguzki Urteaga

Reflexiones sobre el Espacio Público y Participación en las Políticas de Vivienda en Santiago de Chile. Hacia una Práctica Comunitaria / Reflections, on public space and participation in public housinng policies in Santiago de Chile. Towards a community practice

Rodrigo Andrés Mardones

El déficit de transversalidad de género en la Unión Europea / Gender transversality deficit in the European Union

Ángeles Martínez Boyé

Págs 37-60

La construcción de la masculinidad y su relación con la violencia de género / The development of masculinity and relationship to gender violence

$\mathrm{M}^{a}$ Inmaculada López Núñez

Elementos del proceso de mediación que favorecen a su implementación como política social / Elements of the mediation process that benefits implementation as social policy

Paris Alejandro Cabello Tijerina

La mediación escolar y las habilidades sociales en los estudiantes de educación secundaría. Un estudio en institutos de la región de Murcia / School mediation and social skills students in secondary education. A study in institutes of Murcia

María Paz García-Longoria Serrano y Reyna Lizeth Vázquez Gutiérrez

La actuación de los jueces estatales como árbitros privados: un problema de orden público /

State Judge's acting as private arbitrators: a public policy problem

Arnulfo Sánchez García

Págs 137-151

Calidad en los servicios de bienestar en un contexto de crisis económica internacional / Quality in

welfare services in a context of international economic crisis

Eva Sotomayor Morales, Yolanda De la Fuente Robles, Marta García Domingo,

$\mathrm{M}^{\mathrm{a}}$ Luisa Grande Gascón y Tomás Alberich Nistal

Págs 153-179

Contexto de la equidad en los servicios de salud / Context of equity in health services in Mexico

Karla Sáenz López y Delia Téllez Castilla

Los Servicios Sociales en España, puestos a prueba por las personas inmigrantes / Social Services

in Spain, tested by inmigrants

Antonio Gutiérrez Resa

\section{RESEẼAS/REVIEWS}

Rubén Darío Torres Kumbrián. Trabajo Social con Comunidades y Mujeres Musulmanas:

"Diagnóstico de las discriminaciones múltiples" / Social Work with Communities and Muslim women (por Ángeles Martínez Boyé).

Págs 229-234

Manuel Herrera Gómez y José Daniel Barquero Cabrero. Redes sociales: de metáfora a paradigma /

Social Networks: from metaphor to paradigm (por Salvador Gómez García)......

Djamil Tony Kahale Carrillo, Protección a las personas en situación de dependencia / Protection of persons in situations of dependency (por Sara Pérez Martínez). 